Revista Brasileira de Ecoturismo, São Paulo, v.1, n.1, setembro, 2008. ISSN: 1983-9391 - SEÇÃO: ARTIGOS

Pinto, J.B.; Andrade, J.R.L.; Silva, C.E.. Possibilidades de desenvolvimento do Ecoturismo na Área de Proteção Ambiental Moro do Urubu, Aracaju, SE, . Revista Brasileira de Ecoturismo, São

Paulo, v.1, n.1, 2008, pp.42-61.

\title{
Possibilidades de desenvolvimento do Ecoturismo na Área de Proteção Ambiental Moro do Urubu, Aracaju, SE
}

Joyce Barreto Pinto, José Roberto de Lima Andrade, Carlos Eduardo Silva

\section{RESUMO}

A relação entre meio ambiente e turismo é muito intrínseca, sobretudo quando se fala em Unidades de Conservação. O Sistema Nacional de Unidades de Conservação (SNUC) prevê em algumas categorias a intervenção indireta do homem, facilitando a relação com as comunidades envolvidas. O Ecoturismo, segmento do turismo que, diante do fortalecimento da consciência ambiental e da procura por melhoria da qualidade de vida, tem ganhado cada vez mais adeptos nos últimos anos, caracterizando-se como uma alternativa ao desenvolvimento das populações entorno, uma vez que ele considera que os benefícios devem contemplar tanto a conservação das áreas visitadas quanto a questão sócio-econômica da comunidade local. Em vista desta realidade, o presente trabalho se propôs a analisar os aspectos naturais e sócio-culturais na Área de Proteção Ambiental Morro do Urubu e possibilidades para o desenvolvimento do Ecoturismo local. A Área de Proteção Ambiental Morro do Urubu localiza-se na zona Norte de Aracaju e apresenta a única cobertura vegetal com remanescentes da Mata Atlântica na cidade.. Conclui-se que, mesmo incipiente no estado, o Ecoturismo, sobretudo na APA Morro do Urubu tem grandes possibilidades de se transformar em produto ecoturístico.

\section{PALAVRAS-CHAVE}

Ecoturismo, Unidades de Conservação, Morro do Urubu.

\section{Potential Development of Ecotourism in the Area of Environmental Protection of "Morro Urubu", Aracaju, Sergipe, Brazil}

\section{ABSTRACT}

The relationship between environment and tourism is very intrinsic, especially when speaking in units of conservation. The National System of Conservation Units (SNUC) provides in some categories the indirect intervention of people, facilitating the relationship with the communities involved. The ecotourism, tourism segment that before the strengthening of environmental awareness and demand for improved quality of life, has gained more supporters in recent years, characterizing itself as an alternative to the development of the people around. It believes that the benefits should cover both the conservation of the areas visited as a socioeconomic issue of the local community. In view of this reality, this work is proposed to analyze the natural and socio-cultural aspects in the APA Morro do Urubu (Area of Environmental Protection "Morro do Urubu") and possibilities for the development of the ecotourism in this area. The APA "Morro do Urubu" is located in the area north of Aracaju and contains the unique vegetation cover with remnants of Atlantic Forest in the city. It is concluded that even in the nascent state ecotourism, especially in APA "Morro do Urubu" has great potential to grow into ecotouristic product.

\section{KEY-WORDS}

Ecotourism, Protects Areas, APA "Morro do Urubu". 


\section{Introdução}

O Ecoturismo, enquanto segmento de uma atividade econômica, se caracteriza como uma alternativa para promover a inclusão social e uma melhor distribuição de renda de comunidades, melhorando a qualidade de vida da mesma, inclusive no sentido de trazer benefícios para a localidade através de investimentos na infraestrutura básica, por exemplo.

No entanto, a atividade também tem como princípios e objetivos a utilização de recursos naturais conservados, uma vez que o atrativo principal é a natureza conservada, a produção de mínimo impacto ao meio ambiente natural e cultural, inclusive com a destinação do lixo e esgoto, utilização de energias renováveis, análise de capacidade de carga e monitoramento da visitação, dentre outros (KINKER, 2005).

Há ainda um outro ponto em relação à atividade ecoturística bastante relevante. Baseado em sua definição, o Ecoturismo objetiva também a formação (ou quem sabe a multiplicação) de uma consciência ligada à importância da conservação dos ambientes naturais, abordada através da interpretação ambiental, que proporciona uma visão do ambiente como um todo, onde as partes se interrelacionam entre si e dependem uma da outra para um "funcionamento" em equilíbrio, denominado ecossistema.

Dessa forma, todos os envolvidos, seja comunidade ou visitantes, saem beneficiadas e capazes de promover a conservação da área, principalmente quando se trata de uma Unidade de Conservação.

De acordo com o exposto, pode-se concluir que o Ecoturismo é

um segmento da atividade turística que utiliza, de forma sustentável, o patrimônio natural e cultural, incentiva sua conservação e busca a formação de uma consciência ambientalista através da interpretação do ambiente, promovendo o bem estar das populações envolvidas (EMBRATUR, 1994).

Pedrini (2007, p.251) complementa que o Ecoturismo é uma derivação do turismo sustentável realizado em áreas naturais e gerenciado pelas comunidades locais, proporcionando benefícios para a mesma e para a conservação da biodiversidade, utilizando-se das componentes informativa e educacional.

A atividade ecoturística possui uma intrínseca relação com as Unidades de Conservação que são áreas especialmente protegidas destinadas primordialmente à conservação da natureza e ao uso sustentável dos recursos naturais. No Brasil, a Lei 9.985, de 18 de julho de 2000, instituiu o Sistema Nacional de Unidades de 
Conservação da Natureza, o SNUC, que tem o objetivo de regular as complexas relações entre o Estado, os cidadãos e o meio ambiente, propiciando a adequada preservação de significativos e importantes remanescentes dos biomas brasileiros, considerando seus aspectos naturais e culturais.

Estas áreas protegidas são classificadas, segundo o SNUC (BRASIL, 2000), em unidades de proteção integral e de uso sustentável. As Unidades de Conservação que possibilitam a visitação pública, possivelmente caracterizada como Ecoturismo, sob restrições ao órgão responsável, são: as Áreas de Proteção Ambiental, os Parques Nacionais, as Reservas Particulares do Patrimônio Natural, os Monumentos Naturais, Refúgio da Vida Silvestre, Floresta Nacional, Reserva Extrativista e Reserva de Desenvolvimento Sustentável. 2000):

Entende-se por Área de Proteção Ambiental (APA), segundo o SNUC (BRASIL,

uma área em geral extensa, com certo grau de ocupação humana, dotada de atributos abióticos, bióticos, estéticos ou culturais especialmente importantes para a qualidade de vida e o bem-estar das populações humanas, e tem como objetivos básicos, proteger a diversidade biológica, disciplinar o processo de ocupação e assegurar a sustentabilidade do uso dos recursos naturais.

Visto a crescente procura por destinos e roteiros ligados à natureza conservada, o presente trabalho se propôs a estudar a Área de Proteção Ambiental Morro do Urubu, analisando atrativos e possibilidades para o desenvolvimento do Ecoturismo no local.

\section{Métodos e Técnicas}

Durante a pesquisa, tornou-se possível identificar alguns aspectos que se caracterizam como forças e oportunidades para o desenvolvimento do Ecoturismo na Área de Proteção Ambiental Morro do Urubu. Para isso, utilizou-se a seguinte metodologia.

Quanto às técnicas e instrumentos de coleta de dados, foram realizadas as pesquisas documental, bibliográfica e de campo.

Esta última, por sua vez, caracterizou-se por três etapas. No primeiro momento, foram aplicados cinqüenta (50) formulários com a comunidade da área de influência direta do local de estudo. O formulário contou com questões pessoais para o entrevistado, além de perguntas relacionadas à moradia e infra-estrutura e serviços do local. No segundo momento, foram realizadas visitas ao local utilizando a técnica 
veterinário) que trabalham no Parque José Rollemberg Leite. No terceiro momento, foram realizadas entrevistas com um representante do órgão público de Turismo - Secretaria de Estado do Turismo - SETUR -e um representante do órgão de Meio Ambiente - Secretaria Estadual de Meio Ambiente e Recursos Hídricos - SEMARH - além de cinco empresas privadas do Estado que comercializam produtos turísticos e ecoturísticos.

Tanto as entrevistas com a comunidade e com a iniciativa privada quanto para os órgãos públicos seguiram um roteiro, podendo este servir só de suporte para as entrevistas, uma vez que foram semi-estruturadas.

A análise dos dados coletados foi processada através das técnicas qualitativa e quantitativa e representada em quadro explicativo, além de registros fotográficos e textos argumentativos.

\section{Caracterizando a Área de Proteção Ambiental Morro do Urubu}

A Área de Proteção Ambiental Morro do Urubu, localizada na zona Norte de Aracaju, no Estado de Sergipe, apresenta uma área de 213,8724 hectares e é o único remanescente de Mata Atlântica da capital sergipana, um dos motivos que a enquadrou a esta categoria de Unidade de Conservação através do Decreto Estadual $\mathrm{n}^{\circ}$. 13.713, de 14 de junho de 1993.

A Figura 01 mostra o desenho da área da APA, especificando, assim, as áreas de vegetação e de ocupação humana através dos assentamentos subnormais, que. compreende a área de influência direta da APA correspondente à própria área do morro e aos bairros Porto Dantas, Industrial e Coqueiral, todos localizados na cidade de Aracaju.

Dentro desta Unidade de Conservação, está inserido o Parque Municipal José Rollemberg Leite, mais conhecido por Parque da Cidade. A APA é, atualmente, de responsabilidade administrativa da Secretaria Estadual de Meio Ambiente e Recursos Hídricos (SEMARH). No entanto, os 93 Hectares que pertencem ao Parque da Cidade são de competência do Departamento de Desenvolvimento Agropecuário de Sergipe (DEAGRO), vinculado a Secretaria de Estado da Agricultura e do Desenvolvimento Agrário (SAGRI).

O interesse do poder público para a preservação do Morro do Urubu data da década de 1970. Conforme Silva (2004), no ano de 1975, técnicos da prefeitura procuraram a coordenação de Recursos Naturais do CONDESE (Conselho de Desenvolvimento Econômico de Sergipe) para solicitar um levantamento da cobertura vegetal da área com o intuito de implantar uma floresta urbana. Em 1979, a prefeitura adquiriu uma área de 299 hectares para a implantação de uma área de lazer, no caso, o Parque José Rollemberg Leite, que contribuísse também para a preservação de um dos 
Pinto, J. B.; Andrade J. R. de L.; Silva, C.E.

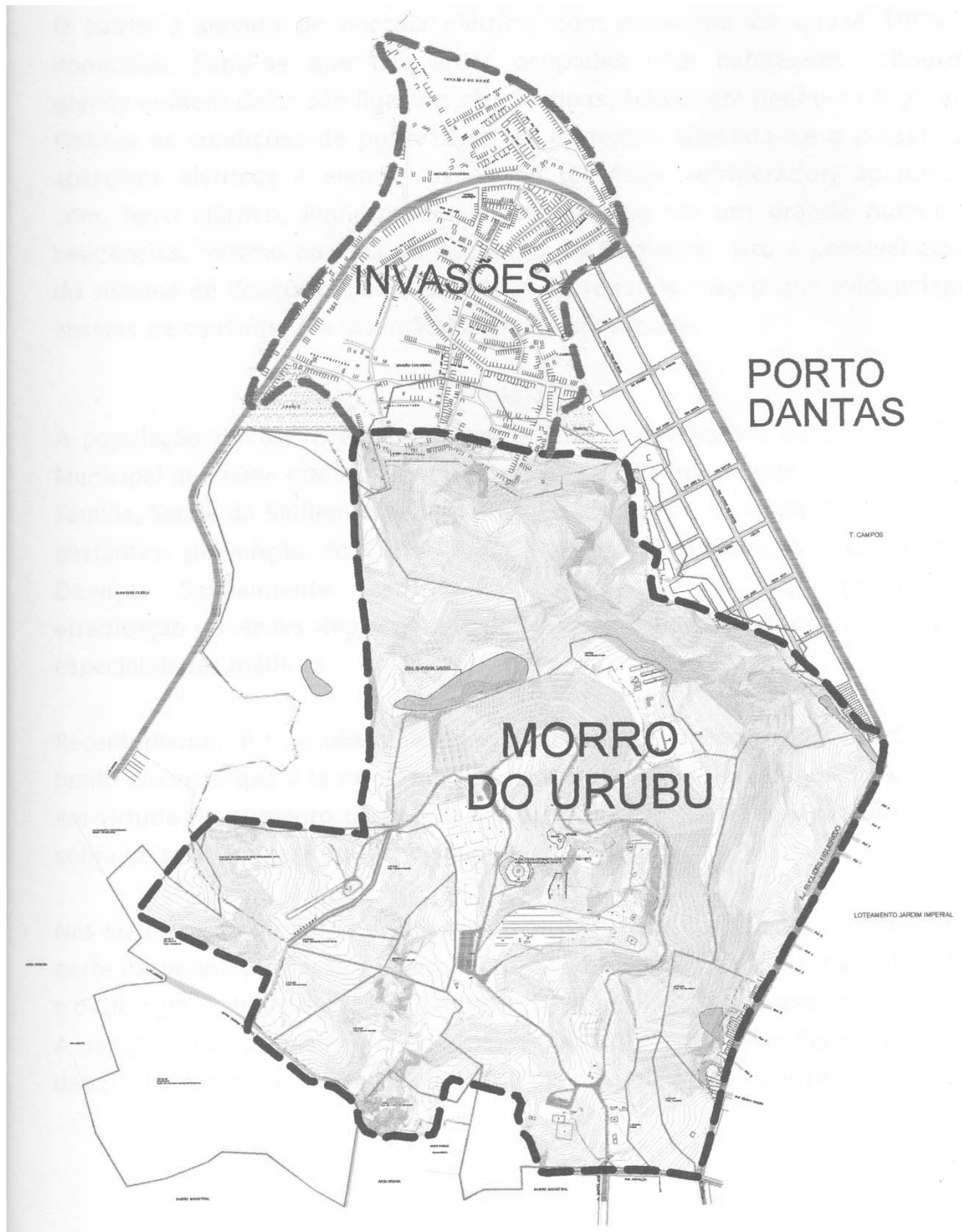

Figura 01 - Mapa da APA Morro do Urubu. Fonte: SEMARH, 2007. 
poucos fragmentos de mata atlântica nativa existente na cidade. Contudo, o funcionamento do parque não impediu o desenvolvimento das atividades agrícolas, tampouco das ocupações e invasões no local. Em vistas da área especificada no decreto de criação da APA, observa-se que no período de 1979 a 1993, parte da mata (cerca de 86 hectares) foi destruída, principalmente por conta da forte pressão urbana no entorno da unidade.

Devido a esses e outros conflitos existentes, no ano de 2000, foi criado o comitê estadual da Reserva da Biosfera da Mata Atlântica (Decreto Estadual n018.638, de 21/02/00), no qual a unidade em estudo está inserida.

Segundo o Diagnóstico Ambiental da APA Morro do Urubu (COOTRAM, 2004) o Porto Dantas, região caracterizada como área rural pela ocupação de sítios com atividades agrícolas e salinas até a década de 1960, iniciou seu processo de urbanização a partir da construção da Avenida Euclides Figueiredo em 1975, quando surgiu então o primeiro loteamento, iniciando assim, o processo de ocupação da zona norte da cidade (caracterizado de forma lenta e gradual). Na década de 1990, com a construção da segunda ponte ligando a capital ao município de Nossa Senhora do Socorro, intensificou-se a urbanização no local, surgindo assim, os assentamentos subnormais do Coqueiral.

Em se tratando das questões físicas e ambientais do local, o Diagnóstico Ambiental da APA traz que a natureza geológica dos terrenos, de característica do grupo Barreiras, classificação do Terciário e estruturas de camadas sub-horizontais, diferenciadas em silte-arenosos e argilas variegadas e de textura siltosa, caracterizam a elevação topográfica do Morro do Urubu. Com essa caracterização, os solos reagem mecanicamente às intervenções, por escavações e remoção da cobertura vegetal, com a queda da resistência à erosão superficial.

Com relação à fauna e flora no local, o diagnóstico ambiental da APA identificou que a formação vegetacional corresponde originalmente a Floresta Mesófila Decídua e à Floresta Mesófila Semidecídua. De acordo com o mesmo documento, podese distinguir na área os ecossistemas manguezal (presente na área de influência indireta, altamente antropizados), mata atlântica e cerrado. O levantamento da flora mostra a pequena variabilidade florística para o ambiente de mata atlântica, tendo sido encontradas 59 espécies nativas do ecossistema.

Em se tratando do inventário da fauna, foram identificadas 40 espécies, predominando as de ampla Valencia ecológica, onívoras e de pequeno porte. Esse resultado reflete o processo de antropização pelo que a região vem passando. 


\section{Resultados e Discussões}

Por caracterizar-se como o único remanescente de mata atlântica da capital sergipana, a área em estudo é considerada um atrativo potencial para o (eco) turismo, apesar de não estar inserido no roteiro turístico local.

Por outro lado, constata-se um apelo histórico identificado no documento Tratado Descritivo do Brasil em 1587, do cronista Gabriel Soares de Souza (SOUZA, p. 66). O autor descreve o local como:

um monte mais alto que os outros, da feição de um ovo, que está afastado da barra algumas seis léguas, pelo qual é a terra bem conhecida. A este monte chamam os índios Manhana, que quer dizer entre eles "espia", por se ver de todas as partes de muito longe.

Inserido no perímetro da APA, o parque da Cidade caracteriza-se por ser uma área de lazer tanto para a comunidade de Aracaju quanto para turistas. Em 19 anos de existência, o Parque passou por duas reformas. A última delas, tendo sido concluída apenas a primeira fase do projeto, foi inaugurada no ano de 2006, em fins do governo de João Alves Filho. As áreas naturais de lazer existentes no parque são muito agradáveis para realização de piqueniques e caminhadas. O Plano de Gestão da APA Morro do Urubu sugere, dentre ações de revitalização do parque, como já foi iniciada, a implantação de paisagismo com espécies nativas.

Em análise sobre o potencial e a situação dos atrativos e infra-estrutura da Área de Proteção Ambiental Morro do Urubu, chegou-se a alguns resultados, propostas ou pontos de visão podem ser visualizados no Quadro 01.

Localizado dentro do Parque da Cidade, o zoológico, encontra-se aberto para visitação pública de terça a domingo das 10 às 17 horas. O local atrai muitos visitantes com o intuito de observar os animais, dentre outros motivos. É possível conhecer espécies nativas e exóticas, como onça pintada, onça suçuarana, leão, ema, cobras, jacarés, siriema, raposa, guaxinim, macaco-prego etc. Existem também ocorrências de visitas de escolas orientadas pelos técnicos do local.

A última reforma no Parque José Rollemberg Leite proporcionou a construção de um prédio, onde se situa a administração do parque que conta com uma biblioteca, uma loja e uma sala de vídeo, importantes para a implementação de ações de Educação Ambiental. Todavia, as mesmas ainda não estão sendo utilizadas para os devidos fins. Além deste prédio, foram construídos também um restaurante e uma área que conta com sanitários e um amplo espaço, onde poderia estar sendo desenvolvida como estrutura de apoio como lanchonete, barraca de artesanato, dentre outros, propor- 
Possibilidades de desenvolvimento do Ecoturismo na ÁPA Moro do Urubu, Aracaju, SE

\begin{tabular}{|c|c|c|c|}
\hline POTENCIALIDADES & SITUAÇÃO ATUAL & $\begin{array}{l}\text { RELEVÂNCIA PARA O } \\
\text { ECOTURISMO LOCAL }\end{array}$ & $\begin{array}{c}\text { SUGESTÕES E PROPOSTAS PA- } \\
\text { RA O DESENVOLVIMENTO DO } \\
\text { ECOTURISMO }\end{array}$ \\
\hline $\begin{array}{l}\text { Áreas naturais de } \\
\text { lazer no Parque Esta- } \\
\text { dual José Rollem- } \\
\text { berg Leite }\end{array}$ & $\begin{array}{l}\text { Áreas conservadas do pon- } \\
\text { to de vista da manutenção, } \\
\text { sendo comprometida em } \\
\text { fins de semana e feriados } \\
\text { ou eventos realizados no } \\
\text { local. }\end{array}$ & $\begin{array}{l}\text { Possibilidade de tra- } \\
\text { balhar com a interpre- } \\
\text { tação ambiental. }\end{array}$ & $\begin{array}{l}\text { Aumentar o número de funcioná- } \\
\text { rios (locais) para manutenção em } \\
\text { dias de maior movimento. Melho- } \\
\text { rar a segurança. }\end{array}$ \\
\hline Biodiversidade & $\begin{array}{l}\text { Elevado grau de desma- } \\
\text { tamento, ocupação de- } \\
\text { sordenada e invasão nas } \\
\text { porções inferiores do } \\
\text { Morro, utilização de agri- } \\
\text { cultura não autorizada. }\end{array}$ & $\begin{array}{c}\text { Espaço potencial para a } \\
\text { implementação de trilhas } \\
\text { (e outros esportes de } \\
\text { aventura) e observação } \\
\text { da flora e fauna, além de } \\
\text { possibilidade de traba- } \\
\text { Ihar com interpretação } \\
\text { ambiental. }\end{array}$ & $\begin{array}{l}\text { Promover o reflorestamento das } \\
\text { áreas mais degradadas da mata } \\
\text { atlântica, trabalhando inclusive a } \\
\text { Educação Ambiental com os mo- } \\
\text { radores e visitantes. }\end{array}$ \\
\hline Zoológico & $\begin{array}{l}\text { Jaulas recém- } \\
\text { reformadas e/ou amplia- } \\
\text { das, porém ainda de má } \\
\text { qualidade para certos } \\
\text { animais. Poucos profis- } \\
\text { sionais especializados. }\end{array}$ & - & $\begin{array}{l}\text { Melhorar as condições de vida de alguns } \\
\text { animais, trabalhar o controle de visitação } \\
\text { em vistas de estresse dos mesmos. Pro- } \\
\text { mover mais visitas orientadas para traba- } \\
\text { Ihar Educação Ambiental. }\end{array}$ \\
\hline $\begin{array}{l}\text { Estrutura de apoio } \\
\text { para a atividade e } \\
\text { ações de Educação } \\
\text { Ambiental no Parque }\end{array}$ & $\begin{array}{l}\text { Estruturas conserva- } \\
\text { das, bem idealizadas, } \\
\text { porém sem funciona- } \\
\text { mento. }\end{array}$ & $\begin{array}{l}\text { Possibilidade de utilização } \\
\text { para praticas de Educação } \\
\text { Ambiental, pesquisa cientifi- } \\
\text { ca, centro de visitação, } \\
\text { atividades socioculturais e } \\
\text { econômicas, estágio, etc. }\end{array}$ & $\begin{array}{c}\text { Viabilizar projetos de Educação Am- } \\
\text { biental e programas de voluntariado } \\
\text { e pesquisa científica no local a fim } \\
\text { de ativar as estruturas. }\end{array}$ \\
\hline Centro hípico & $\begin{array}{l}\text { Utilização para cuidados } \\
\text { e treinamento aos ani- } \\
\text { mais da cavalaria da } \\
\text { Policia Militar do Estado } \\
\text { de Sergipe. }\end{array}$ & - & $\begin{array}{l}\text { Trabalhar a questão da relação homem- } \\
\text { natureza, de bons tratos aos animais. } \\
\text { Além de beneficiar a segurança no local. }\end{array}$ \\
\hline Mirante & $\begin{array}{l}\text { Interessante atrativo por } \\
\text { proporcionar a visualiza- } \\
\text { ção de belas paisagens. }\end{array}$ & $\begin{array}{l}\text { Proporciona a vinda de } \\
\text { visitantes para o local, mes- } \\
\text { mo que não atendendo aos } \\
\text { propósitos do Ecoturismo. }\end{array}$ & $\begin{array}{c}\text { Promover atividades de Educação Ambi- } \\
\text { ental, abordando as questões de degra- } \\
\text { dação ambiental na cidade vista de lá do } \\
\text { alto. }\end{array}$ \\
\hline Teleférico & $\begin{array}{l}\text { Interessante atrativo } \\
\text { para o parque, em boa } \\
\text { condição de manuten- } \\
\text { ção. }\end{array}$ & $\begin{array}{l}\text { Proporciona a vinda de } \\
\text { visitantes para o local, mes- } \\
\text { mo que não atendendo aos } \\
\text { propósitos do Ecoturismo. }\end{array}$ & $\begin{array}{l}\text { Atrelar a Educação Ambiental à visitação } \\
\text { ao equipamento. Provocar o conheci- } \\
\text { mento de que o local é uma área de pro- } \\
\text { teção ambiental e sua importância. }\end{array}$ \\
\hline Equoterapia & $\begin{array}{l}\text { Trabalho social de terapi- } \\
\text { a de excepcionais atra- } \\
\text { vés de eqüinos. }\end{array}$ & - & $\begin{array}{l}\text { Trabalhar a questão da solidarieda- } \\
\text { de e da relação homem-natureza. }\end{array}$ \\
\hline Localização e Acesso & $\begin{array}{l}\text { Proximidade ao centro de } \\
\text { Aracaju, de serviços turísti- } \\
\text { cos e meios de hospeda- } \\
\text { gem e a Ponte Construtor } \\
\text { João Alves. }\end{array}$ & $\begin{array}{l}\text { Possibilidade de ser in- } \\
\text { serido em roteiros no } \\
\text { litoral Norte do Estado. }\end{array}$ & $\begin{array}{c}\text { Inserir o local nos (ou em um dos) } \\
\text { roteiros Trilhas de Pirambu, Xingó e } \\
\text { Cidades Históricas. }\end{array}$ \\
\hline
\end{tabular}

\section{Quadro 01 - Análise das potencialidades identificadas na APA Morro do Urubu.}

Fonte: Elaborado por Joyce Pinto, 2007. 
cionando geração de emprego e renda para as populações vizinhas.

No ponto mais alto do Morro do Urubu encontra-se o centro hípico da Polícia Militar do Estado de Sergipe. Segundo o Zoneamento Ambiental da APA Morro do Urubu (COOTRAM, 2004, p.16), o local caracteriza-se como um atrativo potencial, podendo ser integrado a visitação pública, esclarecendo questões de tratos e cuidados e importância dos animais na atividade militar.

Próximo ao centro hípico e resultado também da última reforma, o Mirante proporciona a visão de boa parte da cidade de Aracaju, além do município de Barra dos Coqueiros, podendo vislumbrar o Rio Sergipe e o oceano mais adiante.

Outra novidade da última reforma, constitui mais uma opção de lazer para os visitantes da APA. O teleférico proporciona em seu percurso a visualização por cima das instalações do zoológico, da mata atlântica, além de partes da cidade de Aracaju e do rio Sergipe.

No parque da Cidade também está localizado um centro de equoterapia destinado a pessoas com deficiência e/ou com necessidades especiais, que também se caracteriza como um atrativo da localidade, podendo ser adaptado para uso turístico.

Agregado aos aspectos acima citados, um fator bastante pertinente para o desenvolvimento do Ecoturismo no que se diz respeito à Área de Proteção Ambiental Morro do Urubu é a sua localização. A mesma encontra-se em área urbana próxima ao centro da cidade de Aracaju e da Orlinha do Bairro Industrial, a poucos minutos da Orla de Atalaia, onde está situada a maior parte dos meios de hospedagem. Além disso, está próxima de pontos de saída da cidade, como rodoviárias e aeroporto.

Com a construção da ponte Construtor João Alves, foi facilitado o acesso da capital ao município de Barra dos Coqueiros, que dá acesso ao litoral norte de Sergipe e vice-versa. A área está próxima também à ponte sobre o Rio do Sal que liga o município de Aracaju ao de Nossa Senhora do Socorro. Tal proximidade, repercute numa possível integração do local em algum dos roteiros apresentados pela Secretaria de Estado do Turismo e comercializado pelas agências de receptivo da cidade de Aracaju.

Em pesquisa documental na Secretaria de Meio Ambiente e Recursos Hídricos - SEMARH - e na administração do Parque da Cidade, e bibliográfica nas Universidades Federal de Sergipe e Tiradentes, além de apresentações em eventos externos e conversas com alunos do Centro Federal de Educação Tecnológica, observou-se que, nos últimos anos, embora em pouca quantidade em relação a outras Unidades de Conservação do Estado, houve um crescimento na busca por estudos na Área de Proteção Ambiental Morro do Urubu e adjacências. Os trabalhos referem-se, dentre outros, à questão social, econômica e ambiental das populações vizinhas da unidade, 
Educação Ambiental e Ecoturismo. Esses estudos contribuem para o conhecimento da situação local, facilitando a formação da consciência ambiental tanto da população local, além de colaborar para o desenvolvimento de outras pesquisas e intervenções na localidade.

Caracteriza-se ainda como fator potencial para o desenvolvimento ecoturístico no local a implementação de trilhas (caminhadas - hiking e trekking). Já é possível encontrar algumas sendo abertas e utilizadas, embora não com finalidade turística.

Além disso, outras atividades lúdico-esportivas podem ser implementadas no local para a atração de turistas. Baseando-se no manual Turismo de Aventura: orientações básicas (BRASIL, 2006), do Ministério do Turismo e de acordo com a observação no local, foi possível identificar as seguintes atividades potenciais: Arvorismo, Atividades ciclísticas, Atividades eqüestres, Caminhadas, Rapel, Tirolesa e Asa delta.

De acordo com a pesquisa, foi possível analisar alguns aspectos que se consolidam como subsídios para a implementação do Ecoturismo no local. Observaram-se aspectos relacionados tanto a comunidade local quanto aos órgãos públicos de turismo e meio ambiente, quanto aos empresários do setor de agências de turismo. Tais subsídios servem para o planejamento da atividade de forma a contribuir para o desenvolvimento local, beneficiando os agentes envolvidos, e para a conservação da área protegida através do envolvimento destes agentes.

\section{Comunidade}

Com relação aos aspectos de moradia, observou-se que a região era caracterizada como área rural pela ocupação de sítios e salinas até as décadas de 1960 e 1970, quando iniciou seu processo de urbanização a partir da construção da Avenida Euclides Figueiredo em 1975, surgindo o primeiro loteamento e da zona norte da cidade, caracterizado de forma lenta e gradual. Em 1980, a população do bairro era de 1.558 habitantes, o que fez com que dois anos depois a região fosse transformada em bairro, denominado Porto Dantas.

Com a desativação das Salinas T. Campos, principal organização econômica e fonte de emprego do local até então, passou-se a desenvolver na região a piscicultura através da Companhia de Alimentos do Nordeste (CALNE). Após falência desta, na década de 1990, as instalações foram desocupadas, o que facilitou a ocupação dos terrenos por famílias atraídas pela construção da ponte sobre o Rio do Sal, surgindo o Coqueiral Sagrada Família, caracterizado por ser uma área de ocupação irregular, com condições de moradia comprometidas, ocorrendo muitas vezes alagamentos e, em locais mais próximos do morro, desabamentos. 
Assim, o processo de expansão urbana da região caracteriza-se por ter ocorrido de forma desordenada provocando o surgimento de assentamentos subnormais muitas vezes caracterizadas por uma má qualidade de vida. Conforme a SEPLAN (2001), existe em Aracaju mais de 52 comunidades em condições de subnormalidade, dentre estas, três delas (Coqueiral, Av. Euclides Figueiredo em direção ao Porto Dantas e Invasão da Margem do Morro do Urubu) - encontram-se no entorno da Área de Proteção Ambiental Morro do Urubu, sendo esta área de preservação de mata atlântica. Destaque para a área que corresponde ao Coqueiral, considerada a mais recente dentre as de maior porte da cidade e que cresce desordenadamente.

A infra-estrutura nos arredores do Morro do Urubu caracteriza-se, dentre outros, pela falta de saneamento básico e muitas construções precárias e improvisadas (devido ao grande número de assentamentos subnormais) na região do Porto Dantas e Coqueiral. Muito dessas construções se deve pelo fato de a comunidade não ter conhecimento que a área é de proteção ambiental, ou mesmo sabendo, não estão sensibilizadas para tal, mesmo julgando importante a conservação. Casos de atuação da Policia Ambiental, Defesa Civil e do órgão estadual de meio ambiente são freqüentes, mas há insistência de alguns moradores em permanecer nos locais oficialmente protegidos e de alto risco, por serem de formação geológica frágil, onde o risco de desabamentos é grande.

Ao serem questionados acerca da APA, 52\% dos entrevistados da comunidade afirmaram não ter conhecimento de que o Morro é uma área de proteção ambiental. Por outro lado, 62,5 \% dos que tinham esse conhecimento julgaram a área Boa. No entanto, os aspectos positivos mencionados para esta avaliação relacionam-se, em sua maioria, a situação do parque. Foram citados como positivos a questão do parque estar bem cuidado, o contato com a natureza, a oportunidade de ver os animais e a beleza cênica do local.

Os aspectos negativos mencionados referem-se à falta de respeito pela população, a necessidade de melhorias, a falta segurança e a utilização da área para esconderijo para bandidos.

\section{Órgão Público de Meio Ambiente}

Em entrevista com o órgão responsável pela Área de Proteção Ambiental Morro do Urubu, a Secretaria de Meio Ambiente e Recursos Hídricos (SEMARH), acerca dos usos e conflitos na Unidade de Conservação, foi possível identificar que a comunidade também utiliza a área com atividades relacionadas à ocupação desordenada e à moradia ilegal, resultando no desmatamento da mata atlântica, o que implica em crime ambiental, de acordo com a Lei no. 11.428, de 22 de dezembro de 2006, que dispõe sobre a utilização e proteção da vegetação nativa do Bioma Mata Atlântica e com 
os artigos 40 e 50 da Lei n. 6.905, de 12 de fevereiro de 1998, que trata das sanções penais e administrativas derivadas de condutas e atividades lesivas ao meio ambiente. O artigo 40 (BRASIL, 1998) fala da implicação de dano direto ou indireto às Unidades de Conservação e a outras áreas protegidas legalmente. Já o artigo 50 (BRASIL, 1998) trata propriamente do desmatamento, exploração economicamente ou degradação florestal, seja ela plantada ou nativa, em terras de domínio público ou devolutas, sem autorização do órgão competente.

Há também na área, casos de atividades agrícolas não autorizadas, retirada de materiais como areia e a criação de uma lixeira.

Muitos desses conflitos e usos são conseqüências da exclusão social e da situação da moradia referente principalmente à renda dos moradores, já mostrado anteriormente, além da infra-estrutura básica e serviços no local.

Para a mitigação dos problemas mostrados neste item e no 5.3.1, relacionados à não conservação da unidade que resultam na não concretização dos objetivos determinados no SNUC para uma APA, a Secretaria de Estado do Meio Ambiente e Recursos Hídricos em 2007 começou a, de fato, pensar a gestão na APA Morro do Urubu. Conforme o Sistema de Gestão Ambiental para a APA Morro do Urubu (2005), até então não havia uma administração estruturada para a área capaz de atender as demandas locais.

A Área de Proteção Ambiental Morro do Urubu foi decretada em 14 de junho de 1993, não tendo sido realizada consulta pública para a criação da mesma, tendo em vista que neste período ainda inexistia o Sistema Nacional de Unidades de Conservação - SNUC.

Diante da realidade do local, o atual governo (2006-2010) está desenvolvendo ações para a gestão da área como um todo. A primeira incitativa do mesmo para a APA foi a indicação de um técnico para a gestão da área. Outras ações foram realizadas com o comprometimento de gerir melhor o local a fim de minimizar os conflitos, como reuniões com o Departamento de Desenvolvimento Agropecuário de Sergipe DEAGRO para firmar parcerias, uma vez que a mesma é responsável pelo Parque da Cidade, visitas ao local para reconhecimento da situação atual da área e das comunidades do entorno, além de sinalização da área, mostrando a delimitação do polígono da mesma.

Pretende-se, ainda, criar uma sede administrativa no local e um pólo de Educação Ambiental e pesquisa, firmando parcerias com instituições como Universidade Federal de Sergipe, Universidade Tiradentes, Centro Federal de Educação Tecnológica de Sergipe, Policia Ambiental, dentre outros.

Como já foi mencionado, em 2006, foi realizada uma reforma nas instalações do Parque José Rollemberg Leite, ou Parque da Cidade, que melhorou alguns aspectos a serem utilizados para o turismo no local e para a própria gestão da unidade. Fora isso, a própria elaboração de um Diagnostico Ambiental e de um Plano de Gestão para a APA caracterizaram-se como uma importante ação para a gestão da área. 
Quando questionado acerca do desenvolvimento do Ecoturismo na área, foi afirmado pelo gestor que o local possui aspectos positivos para a prática da atividade. Por outro lado, a criação do pólo de Educação Ambiental pode colaborar muito para o desenvolvimento do Ecoturismo no local.

Em pesquisa no site da SEMARH, pôde-se identificar na matéria Secretário visita APA do Morro do Urubu (SERGIPE, 2008) o interesse do órgão administrador da unidade em implantar o Ecoturismo como atividade alternativa para a conservação do local). Segundo SEMARH, "Será feita uma gestão compartilhada entre os dois órgãos. Com a união de esforços entre a SEMARH e a EMDAGRO, a APA do Morro do Urubu, será utilizada para fins de estudos e pesquisas científicas, Educação Ambiental, como também, fonte de lazer e Ecoturismo".

O Plano de Gestão da APA Morro do Urubu traz algumas propostas para o sistema de gestão da área. De acordo com o Decreto Estadual no. 15.405 (SERGIPE, 1995), a administração da APA é de responsabilidade da Secretaria de Estado do Meio Ambiente, no entanto até o ano de 2006, a unidade estava sob cuidados da ADEMA (Administração Estadual do Meio Ambiente), responsável pela fiscalização e licenciamento ambiental no Estado de Sergipe.

Com a reestruturação da SEMA, atualmente denominada SEMARH, a administração do Morro do Urubu está sob responsabilidade desta.

O Plano de Gestão da unidade propõe para a melhoria da administração das Unidades de Conservação estaduais, sobretudo a APA Morro do Urubu, a criação e a implantação de um Sistema Estadual de Unidades de Conservação, vinculado a SEMARH, no mesmo nível hierárquico da ADEMA e não subordinado, como pode ser visualizado na figura 02.

\section{Órgão Público de Turismo}

De acordo com o representante da Secretaria do Turismo de Sergipe, o Ecoturismo está entre os três segmentos priorizados pela política pública estadual de turismo, considerando a diversidade do potencial natural nas áreas de exploração, além do Ecoturismo é trabalhado o Turismo de Sol e Praia e o de Negócios e Eventos. Entre os produtos que exploram o Ecoturismo pode-se destacar a Rota Aracaju-Xingó, a Rota Costa das Dunas e Manguezais, o Roteiro Xingó, Roteiro Segredos de Tieta, Roteiro Trilhas de Pirambu e Roteiro Foz do Rio São Francisco.

Ao ser questionado se o poder público, ao desenvolver esses roteiros, leva em consideração os princípios do Ecoturismo de inserção da comunidade e a preservação do ambiente, o assessor técnico da SETUR complementou que no início do ano 2007 a Secretaria de Estado do Turismo reuniu a cadeia produtiva representada pelos membros do Fórum Estadual de Turismo, trade turístico, Sistema "S", representantes de 
classes, ONG's e OSCIP's, Instituições de ensino e Instituições financeiras para discutir o planejamento do setor ao longo de quatro anos, com ações distribuídas em cinco programas estratégicos: Satisfação do Turista, Excelência na Gestão do Turismo, Inclusão Social pelo Turismo, Cadeia Produtiva do Turismo e Competitividade do Turismo.

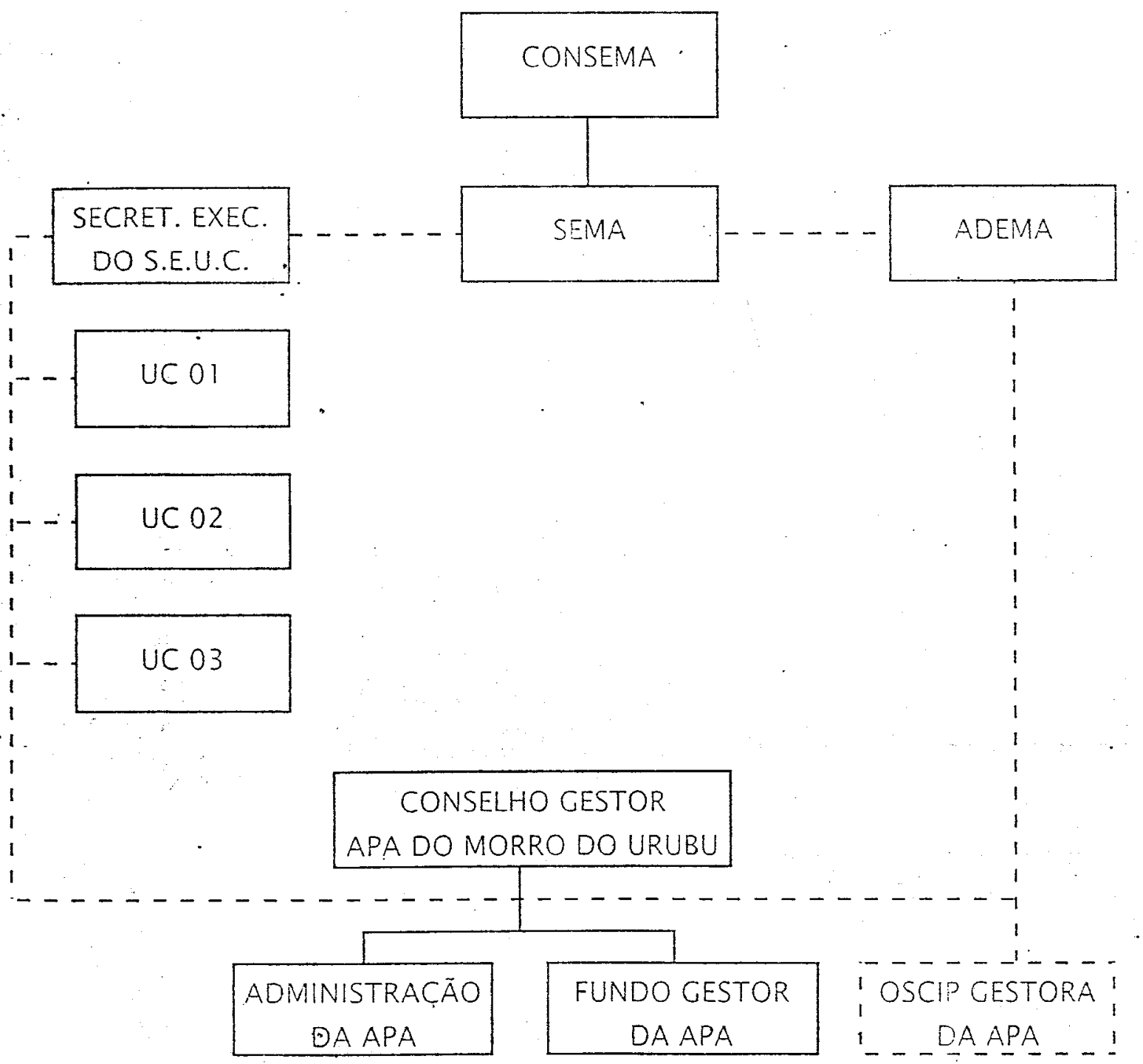

Figura 02 - Proposta Organizacional para o Sistema Estadual de Unidades de Conservação e para a Gestão Ambiental da APA Morro do Urubu. Fonte: Cootram ( 2005). 
Segundo a SETUR, é possível perceber o envolvimento da comunidade no Programa de Excelência na Gestão do Turismo onde foi priorizado a institucionalização das instâncias de Governança nas regiões turísticas do Estado com formato tripartite permitindo o envolvimento do poder público, setor privado e terceiro setor, como os Conselhos de Turismo, que adotam critérios e diretrizes do Programa de Regionalização do Turismo - Roteiros do Brasil e do Programa de Desenvolvimento do Turismo no Nordeste do Brasil - PRODETUR/NE.

Quanto à preservação dos ambientes, ele afirma que se torna assegurada em diversas ações. Por exemplo, os municípios do Pólo Costa dos Coqueirais que ainda não haviam elaborado seus planos diretores puderam fazê-lo com recursos do PRODETUR/NE, garantindo aprovações de leis de controle do uso do solo e dos recursos naturais bem como planejando o desenvolvimento e futuro das comunidades.

O desafio do órgão para o ano 2008, de acordo com a SETUR, é reunir o público de interesse para rediscutir os roteiros turísticos e avaliar o nível de envolvimento das comunidades locais e o impacto da geração de renda. Um bom exemplo é a articulação com o DEAGRO para fortalecer o Turismo Rural na Agricultura Familiar, otimizando o uso de produtos típicos regionais e valorizando produções como a mandioca, apicultura, ovinocaprinocultura, entre outros.

Em relação à responsabilidade para com uma Área de Proteção Ambiental e a venda de roteiros turísticos nessas unidades e em ambientes naturais em geral, o técnico da SETUR comenta que entende que é dever tanto dos órgãos públicos de turismo e meio ambiente, turistas e moradores preservar a área. Além disso, deve haver respeito à legislação ambiental, e a sustentabilidade das áreas naturais exploradas pelo turismo. O Estado de Sergipe tem seu potencial turístico associado aos recursos naturais, indicando que o controle do uso desses recursos deve estar presente em todas as discussões acerca do desenvolvimento do setor.

Sobretudo, a SETUR afirma que as áreas de proteção ambiental são assim destinadas por exigir uma atenção maior em relação à exploração, devendo ser observado o tipo de proteção definida para algumas áreas, já que atualmente vem aumento o recorte geográfico das áreas de proteção ambiental, e deve-se ponderar que a preservação, respeito e controle do uso dos recursos naturais e do patrimônio cultural não estão em torná-los intocáveis, mas em orientar suas limitações e as possíveis formas de uso.

Dessa forma, o entrevistado julga a Área de Proteção Ambiental Morro do Urubu uma área com um apelo natural, além de estar inserida na capital Aracaju, considerada o grande portão de entrada do turismo no Estado e que oferece também equipamentos e serviços que permitem satisfatoriamente a visita de turistas ao local. Para ele, o próximo passo importante para inseri-lo nas rotas turísticas, pode ser o envolvimento ou sensibilização dos gestores da área com agentes de turismo receptivo, visto que estes são responsáveis pela comercialização dos produtos turísticos. Assim, o local torna-se preparado para ser comercializado tanto nas esferas local, estadual e 
nacional.

Atualmente, não existem projetos por parte da secretaria de Turismo para se trabalhar o turismo no local especificamente. No entanto, o representante comenta que, no âmbito da política pública estadual de turismo, o desenvolvimento do Ecoturismo é visto de forma regionalizada e não direcionada a determinadas áreas, nesse contexto a área pode perfeitamente ser beneficiada com as ações de estruturação do Turismo promovidas pela Secretaria de Estado do Turismo em parceria com o Ministério do Turismo, desde que busquem o Órgão Oficial de Turismo para entender as formas de parceria e colaboração e procurem otimizá-las para sua área. Como exemplo, pode-se citar a realização de oficinas de qualificação do setor, orientadas para diversos segmentos, oficinas de roteirização do turismo, entre diversos trabalhos de sensibilização e mobilização, nos quais os servidores turísticos da APA do Morro do Urubu poderão ser inseridos.

\section{Agências de Turismo Receptivo}

A pesquisa com agências de receptivo do Estado de Sergipe teve o intuito de levantar informações acerca de alguns indicadores, como a visibilidade destas em relação aos roteiros ecoturísticos existentes no Estado de Sergipe e contexto da conservação dos mesmos, o conhecimento dos operadores destas agências em relação à área de estudo deste trabalho e o interesse e opinião na implantação e comercialização da APA Morro do Urubu.

Quando questionadas sobre seus conhecimentos acerca do atual desenvolvimento ecoturístico em Sergipe, a maioria das agências concorda que o segmento é uma opção rentável e propensa ao crescimento no Estado. No entanto, duas agências afirmaram não existir roteiros para Ecoturismo. Uma delas se ateve à afirmação de que as agências de Sergipe não trabalham com Ecoturismo, enquanto outra comentou que até existem roteiros potenciais, mas que as empresas não exploram de forma a relacionar a atividade com os cunhos educacional e conservacionista, premissas do Ecoturismo.

Apenas uma agência não respondeu se acha importante a preocupação com a venda de roteiros turísticos em ambientes naturais, as demais concordaram que é necessário o planejamento sustentável da atividade. As mesmas citaram que devem ser levados em consideração aspectos como a sensibilização do trade e da comunidade envolvida, a Educação Ambiental, estudos de capacidade de carga turística, recolhimento do lixo, formação de guias mirins locais e projetos de reflorestamento, por exemplo.

De acordo com a pesquisa, notou-se que nenhuma agência tinha conhecimento de que a área era uma Unidade de Conservação. Alguns sabiam do local por rela- 
cionar com a existência do zoológico, e mesmo, assim, não costumam nos dias atuais visitar o parque, mesmo depois da reforma.

Ao serem abordados com a questão de quem tem responsabilidade para com uma Área de Proteção Ambiental, foi unânime que o órgão ambiental é e deve ser o principal responsável. No entanto, $60 \%$ dos entrevistados afirmaram que o órgão de turismo e os moradores também devem ter esta responsabilidade e $50 \%$ concordam que este dever é também dos turistas.

Quatro agências responderam a questão sobre a visão de possibilidade de implantação do Ecoturismo na APA Morro do Urubu. Destas, $75 \%$ afirmaram que é possível a implantação da atividade no local. Dentre os aspectos positivos para tal implantação, comentaram a questão do acesso e da localização, a possibilidade de trabalhar com Educação Ambiental em escolas da cidade, a existência de espaços para lazer dentre outros atrativos, como a visibilidade do alto do morro. No entanto, eles julgam necessário para o desenvolvimento da atividade na APA alguns fatores como: melhoria na infra-estrutura de lazer e serviços turísticos, iniciativa e comprometimento do poder público e divulgação.

Diante das entrevistas, $60 \%$ das agências demonstraram interesse em comercializar a APA Morro do Urubu, principalmente nas esferas local e regional, inicialmente.

\section{Conclusões}

Embora a atividade ecoturística ainda esteja incipiente em Sergipe, observa-se certo potencial para o desenvolvimento do segmento no Estado, tanto devido aos recursos naturais existentes quanto à necessidade de alternativas sustentáveis para a geração de emprego e renda para a população e conservação destes recursos.

A partir das potencialidades identificadas para o Ecoturismo na área de estudo e das entrevistas com os órgãos e agências, observou-se que o planejamento do Ecoturismo na Área de Proteção Ambiental Morro do Urubu, de acordo com seus princípios, torna-se possível, no entanto, algumas diretrizes são necessárias para a implementação da atividade no local, a saber:

- Melhorar as condições de ensino, saúde, saneamento e segurança dos bairros de influência direta da APA Morro do Urubu;

- Proporcionar cursos de qualificação e capacitação profissional ligados a cadeia produtiva do turismo;

- Caracterizar e contextualizar a região da APA para a comunidade, mostrando seus atributos naturais, sociais, culturais e seus principais problemas; 
- Sensibilizar a população do entorno e a população em geral para a importância da preservação da APA;

- Sensibilizar órgãos públicos e iniciativa privada para a necessidade de ações com responsabilidade sócio-ambiental no local.

- Criar estrutura de administração da APA no local, inclusive com parcerias de OSCIPs e comunidade local;

- Promover a fiscalização dos usos indevidos no local, se possível pela própria comunidade e com parceria da Policia Ambiental;

- Proporcionar geração de emprego e renda através de atividades ligadas a conservação natural;

- Proporcionar ações de fomento a criação de cooperativas nas comunidades do entorno.

A falta de projetos que trabalhem com a inclusão das comunidades do entorno da APA Morro do Urubu, tanto no beneficiamento socioeconômico quanto em ações que visem à sensibilização e a aproximação destas com a área pode comprometer a implantação e consolidação do local como produto turístico.

Da mesma forma, a falta de comprometimento dos órgãos públicos envolvidos e da iniciativa privada também podem tornar-se ameaças ao novo produto ecoturístico no Estado de Sergipe.

Em se tratando da comercialização do produto, conclui-se que, mesmo não tendo conhecimento do local, a maioria das agências de turismo receptivo vê possibilidade e tem interesse num novo produto ecoturístico para o mercado sergipano, principalmente por se tratar de um segmento pouco explorado no Estado.

Uma vez transformado em produto turístico, o local pode ser integrado aos roteiros Xingó, Trilhas de Pirambu e Cidades Históricas. Tais produtos se tornam possíveis tanto devido aos municípios abrangentes como aos segmentos turísticos desenvolvidos. No entanto, o atrativo se encaixa melhor nos dois últimos roteiros (Cidades Históricas e Trilhas de Pirambu). Visto que a última reforma contemplou a APA com a imagem de Nossa Senhora da Conceição, a Secretaria de Estado da Cultura tem interesses em implementar o turismo religioso e cultural na área, podendo então a área ser facilmente agregada ao roteiro das Cidades Históricas. Em relação ao roteiro Trilhas de Pirambu, a atividade que pode ser desenvolvida na APA atrelada à localização da mesma favorece também a inserção do Morro do Urubu neste roteiro.

As diretrizes sugeridas são consideradas capazes de serem implementadas a fim de proporcionar o surgimento de ações e projetos envolvendo os três setores através de parcerias para que o desenvolvimento do Ecoturismo na Área de Proteção Ambiental Morro do Urubu seja possível e viável, do ponto de vista econômico, social e ambiental, o tripé básico para a sustentabilidade. 


\section{Referências}

BRASIL. Lei no 9.985 de 18 de julho de 2000. Institui o Sistema Nacional de Unidades de Conservação da Natureza - SNUC. Brasília, DF, 18 jul 2000.

BRASIL. Lei $n^{\circ} 11.428$ de 22 de dezembro de 2006. Dispõe sobre a utilização e proteção da vegetação nativa do Bioma Mata Atlântica, e dá outras providências. Brasília, DF, 22/12/2006.

BRASIL. Lei no 6.905 de 12 de fevereiro de 1998. Dispõe sobre as sanções penais e administrativas derivadas de condutas e atividades lesivas ao meio ambiente, e dá outras providências.. Brasília, DF, 12/02/1998.

BRASIL. Ministério do Turismo. Secretaria Nacional de Políticas de Turismo. Turismo de aventura: orientações básicas / Ministério do Turismo, Coordenação - Geral de Segmentação. - Brasília:Ministério do Turismo, 2006.48 p.

COOTRAM. Diagnóstico Ambiental - Bases para a Elaboração do Plano de Gestão da APA Morro do Urubu. ADEMA: Aracaju, 2004.

2005.

.Sistema de Gestão Ambiental para a APA Morro do Urubu. ADEMA: Aracaju,

EMBRATUR. Diretrizes para uma Política Nacional de Ecoturismo. Coordenação de Sílvio Magalhães e D. Hamú M. de la Penha. Brasília, 1994.

KINKER, Sônia. Ecoturismo e conservação da natureza em parques nacionais. 2. ed. Campinas, SP: Papirus, 2005.

PEDRINI, Alexandre Gusmão. A Educação Ambiental no Ecoturismo brasileiro: passado e futuro. In: SEABRA, Giovanni (org). Turismo de Base Local: identidade cultural e desenvolvimento regional. João Pessoa: Editora Universitária UFPB, 2007.

SERGIPE. Decreto no 13.713 de 14 de junho de 1993. Institui a criação da área de Proteção Ambiental Morro do Urubu. Aracaju, 14 jun 1993.

. Decreto $n^{0} 15.405$ de 13 de julho de 1995 . Altera os artigos $2^{\circ}$ e $4^{\circ}$ do Decreto 13.713 de 14 de junho de 1993, que institui Área de Proteção Ambiental, e dá outras providências.

. Secretário visita APA do Morro do Urubu. Disponível em:

www.sema.se.gov.br. Acesso no dia 23/01/2008. 
Possibilidades de desenvolvimento do Ecoturismo na ÁPA Moro do Urubu, Aracaju, SE

SEPLAN/ PMA. Plano Estratégico Municipal para Assentamentos Subnormais PEMAS. Aracaju: SEPLAN/ PMA, 2001.

SETUR. Plano Estratégico do Turismo em Sergipe. 2007-2010. Aracaju, 2007.

SILVA, Kercy da Cunha Teixeira. O urbano, o rural e o ambiental nas transformações do Bairro Porto Dantas, no norte da cidade de Aracaju-SE. São Cristóvão, SE:

(Dissertação de mestrado). Universidade Federal de Sergipe, 2004.134 p.

SOUZA, Gabriel Soares de. Tratado Descritivo do Brasil em 1587.

Joyce Barreto Pinto: Instituto Socioambiental Árvore

Email: joyce@arvore.org.br

Link para o currículo Lattes: http://lattes.cnpq.br/0356680973658857

José Roberto de Lima Andrade: Universidade Federal de Sergipe

Email: roblima@uol.com.br

Link para o currículo Lattes: http://lattes.cnpq.br/2514532556386441

Carlos Eduardo Silva: Instituto Socioambiental Árvore

Email: carlos@arvore.org.br

Link para o currículo Lattes: http://lattes.cnpq.br/3700554054159220

Data de submissão: 06 de maio de 2008

Data de aceite: 04 de julho de 2008 